\title{
PERCEPTION OF FIRST-YEAR GEOLOGY STUDENTS ON THE TECTONIC PLATES THEORY
}

\author{
Katrivanos D. E. ${ }^{.,}$, Makri K. ${ }^{2}$ \\ ${ }^{1}$ Aristotle University of Thessaloniki, Department of Geology, 54124 Greece Thessaloniki \\ e-mail:ekatriva@geo.auth.gr \\ ${ }^{2}$ Aristotle University of Thessaloniki Department of Geology, 54124 Greece Thessaloniki \\ e-mail:kmakri@geo.auth.gr
}

\begin{abstract}
This paper examines alternative ideas and perceptions of first-year students of the Department of Geology at the Aristotle University of Thessaloniki, on the theory of tectonic plates, prior to completion of relevant courses. There is partial confusion both in terms of the conceptual background, as well as on the causal links between geological phenomena associated with the movement of tectonic plates. One out of two questioned students has systematic and consistent knowledge on the principles of the theory of tectonic plates, both at a conceptual and at a deterministic level, as well as in terms of geometric, kinematic and dynamic analysis.
\end{abstract}

Keywords: alternative ideas, misconceptions, conceptual confusion, causal relationships, lithosphere structure, convergence, divergence, tectonic plates.

\section{Introduction}

The effort to detect, record and analyze the alternative ideas of children on Natural Sciences starts from the extensive research activity of Piaget (1929). In doing so, various data collection methods have been used worldwide, such as written statements, posters, business cards, mental tests, interviews, questionnaires, experiments, projects, etc. (Driver et al., 2000 \& Javeau C., 2000). At the present paper, a closed multiple choice questionnaire was selected as the preffered method for obtaining the data (Paraskevopoulos, 1993). The performance of students in objective-type questions, such as multiple choice questions, depends on their reading ability (Alexopoulos, 1998). Due to the age of the respondents, it is assumed that the reading ability is adequate.

The subject of the questionnaire was selected on the basis that the theory of tectonic plates is a single theory for the interpretation of geological phenomena, processes and mechanisms, relevant to the theory of "Big Bang" in Physics, or the Darwinian evolution theory in Biology, or the atomic theory in Chemistry. Moreover, the theory of tectonic plates allows a holistic approach to the teaching of Natural Sciences.

It is important to clarify that the surveyed students had not been taught anything relevant to the theory of tectonic plates before completing the questionnaire. The aim of the present work is to point out questions rather than to solve them. 
The key questions that this paper deals with are:

- Do first-year geology students know that plate-related events are dynamic rather than static?

- Does the perception about the constant movement and change belong to their cognitive system in a consistent and systematic way?

- Do the students know what causes the movement of tectonic plates and what the consequences are?

The objective of the present work is to detect the perceptions, correct or incorrect, of the students, both at the conceptual and the deterministic level. It is also clear that this effort was a part of a holistic vision of our planet as a dynamic system, a sum of interactions and continuous changes.

\section{Methodology}

The research took place in Thessaloniki, Greece, on the $30^{\text {th }}$ of November 2009, during class hours of the first semester. A close-end multiple choice questionnaire on the theory of tectonic plates was distributed to first-year students of Geology $(\mathrm{N}=49)$. The questionnaire comprised of five (5) questions; each of them had five (5) possible answers. Attempt was made in order to include a list of all essential elements of the theory of tectonic plates in the above mentioned small number of questions, in order to point out the key words of the above theory. The questions are related to the movements of the plates; more specifically, which is the rate of movement (question 1), which is the cause of plate movement (question 2), what is the effect of the movement on convergent boundary (question 3), how the lithosphere is structured (question 4), and what is the effect of the movement on divergent boundary (question 5). This way, it is studied whether the students can only understand the purely geometric structure of the lithosphere, or furthermore its kinematic level and ultimately percept the dynamic causes of tectonic plate movement. The two questions on the converging and diverging margins, link the theory of tectonic plates to the widely known geological phenomena, such as earthquakes and volcanoes. Through these questions, the level of perception of students in geological terms and concepts, such as convergent-divergent tectonic plates, convection currents of the mantle, core-mantle-crust, midocean ridges, earthquakes, volcanoes, subduction zones etc. are studied, since geological structures as well as geological processes and mechanisms are included. The level of perceptions of the outcome of tectonic plates movement, as well as the causal links between various geological phenomena is also investigated. The order of questions in the questionnaire was designed so as to avoid the definition of a way of thinking, i.e. not to lead the students to specific answers and to avoid the effect of luck in the responses. So, two questions about the rate and the causes of tectonic plate movement were selected for the beginning of the questionnaire, since one possible answer was that the plates do not move an option that is associated with one of the main objectives of this research.

\section{Results - Conclusions}

From the analysis of responses using Microsoft Excel formulae, the following results were obtained. In the $1^{\text {st }}$ question about the rate of movement of the tectonic plates (Table 1), half of the students $(53.1 \%)$ responded correctly $(\mathrm{cm} / \mathrm{yr})$. From the remaining responses, the response rate that the move is given better in ( $\mathrm{cm} / \mathrm{Myr}$ ) was assigned at the questionnaire to check the level of internal consistency and stability of students' knowledge. The higher proportion $(32.7 \%)$ in this response reveals the internal inconsistency and uncertainty of the students. The remaining $14.3 \%$ who chose to answer $(\mathrm{km} / \mathrm{yr})$, or (m/yr) probably indicates lack of any relationship to the geological science (Fig. 1). 
Table 1.

\begin{tabular}{|c|c|}
\hline $\begin{array}{l}\text { 1st Question: Tectonic plates move at an average rate } \\
\text { that is best described by: }\end{array}$ & Answers \\
\hline a. $\mathrm{km}$ per year $(\mathrm{km} / \mathrm{yr})$ & 5 \\
\hline b. cm per year $(\mathrm{cm} / \mathrm{yr})$ & 26 \\
\hline c. m per year (m/yr) & 2 \\
\hline d. $\mathrm{cm}$ per million years $(\mathrm{cm} / \mathrm{Myr})$ & 16 \\
\hline e. none of them, since the tectonic plates do not move & 0 \\
\hline 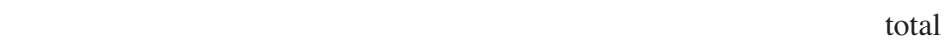 & 49 \\
\hline
\end{tabular}

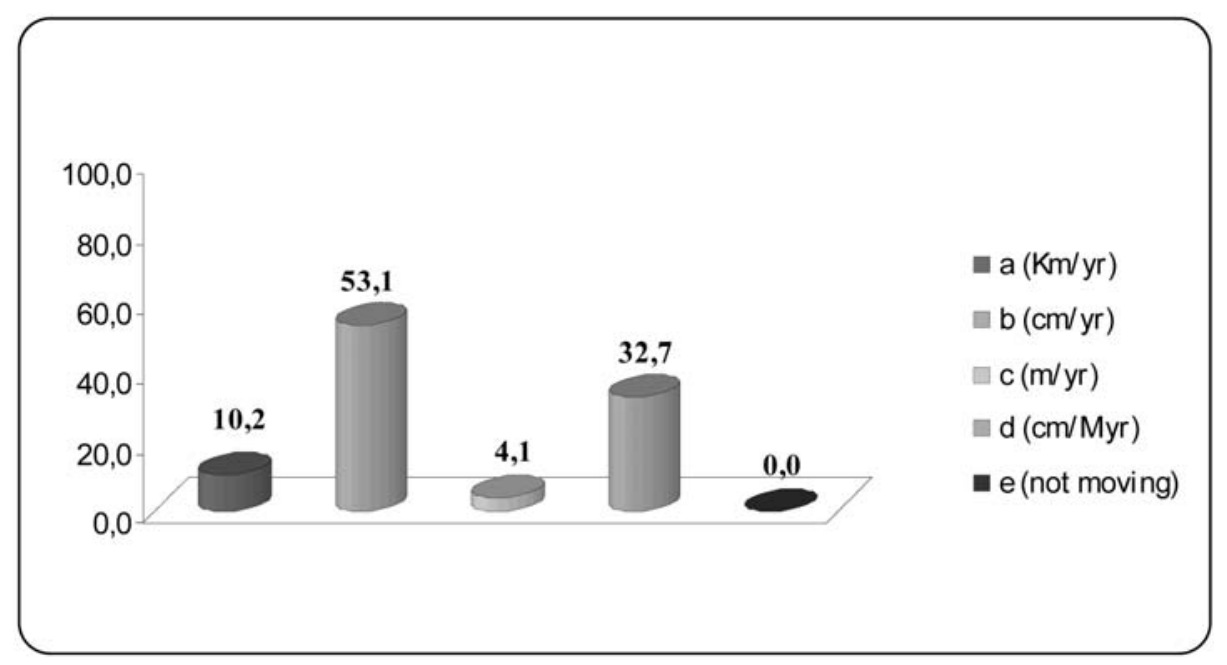

Fig. 1: Percentage of answers to $1^{\text {st }}$ Question.

In the $2^{\text {nd }}$ question on the causes of the movement of tectonic plates (Table 2), one out of two students $(51 \%)$ answered correctly (transportation currents carry material and energy of the mantle). The second most popular answer (30.6\%) (the motion due to rotation of the mantle around the core), shows a lack of understanding of the conceptual content of "convection currents of the mantle". It is presumed that the students have seen a diagram with arrows motion at the mantle and therefore that is the reason for choosing this response. It is obvious that there is also at this issue internal inconsistency and confusion. Percentage of $18.4 \%$ chose responses related to the density and gravitational pull, answers that are clearly situated in the field of upper secondary school, far from any connection to the geological science. It is noted as a positive remark that none of the students responded that the tectonic plates do not move (Fig. 2). 
Table 2.

\begin{tabular}{|l|c|}
\hline \multicolumn{1}{|c|}{ 2nd Question: Tectonic plates movement is the result of: } & Answers \\
\hline a. mantle and core different densities & 4 \\
\hline b. energy of the sun and the attraction between the planets & 5 \\
\hline c. the rotation of the mantle around the core & 15 \\
\hline d. mantle convection currents that transport material and energy & 25 \\
\hline e. none of them, since the tectonic plates do not move & 0 \\
\hline & total \\
\hline
\end{tabular}

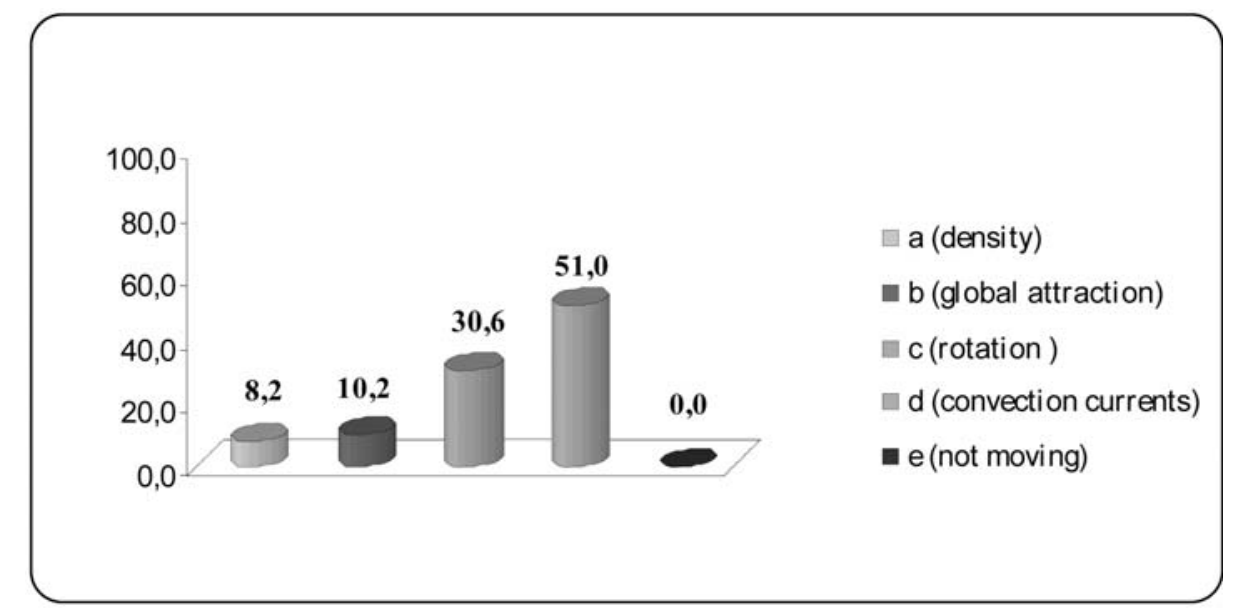

Fig. 2: Percentage of answers to $2^{\text {nd }}$ Question.

In the $3^{\text {rd }}$ question on the convergence of tectonic plates (Table 3), the same percentage of correct answers $(53.1 \%)$ was repeated with great consistency. It is formed, at a secure way, a picture where one in two respondents owns the principles of the theory of tectonic plates (Fig. 3).

Table 3.

\begin{tabular}{|l|c|}
\hline \multicolumn{1}{|c|}{$\begin{array}{c}\text { 3rd Question: When two tectonic plates converge, we expect to find } \\
\text { at their boundary: }\end{array}$} & Answers \\
\hline a. superficial and deep earthquakes & 9 \\
\hline b. volcanoes and mountains & 4 \\
\hline c. subduction zone & 26 \\
\hline d. all of them & total \\
\hline e. none of them & 49 \\
\hline
\end{tabular}




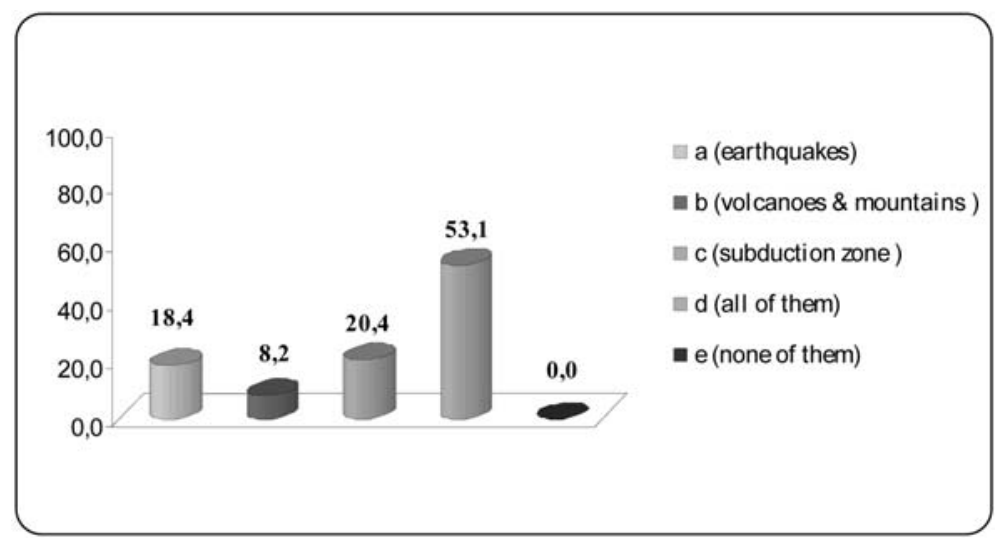

Fig. 3: Percentage of answers to 3rd Question.

The $4^{\text {th }}$ question about the structure of the lithosphere (Table 4), the same percentage of correct answers $(51 \%)$ is repeated. It is clear that there is a fully polarized sample of respondents between those who possess the basic theory and those who do not, at a ratio of 1 to 1 . The rate of $18.3 \%$ that chooses a totally incorrect response, that the lithosphere consists of the core plus mantle, away from any relationship and contact with the geological science, is repeated (Fig. 4).

\section{Table 4.}

\begin{tabular}{|l|c|}
\multicolumn{1}{|c|}{ 4th Question: The lithosphere consists of: } & Answers \\
\hline a. the core and the mantle & 6 \\
\hline b. the crust and the lower mantle & 12 \\
\hline c. the crust and the upper mantle section & 25 \\
\hline d. the core and the lower mantle & 3 \\
\hline e. none of these & 3 \\
\hline & total \\
\hline
\end{tabular}

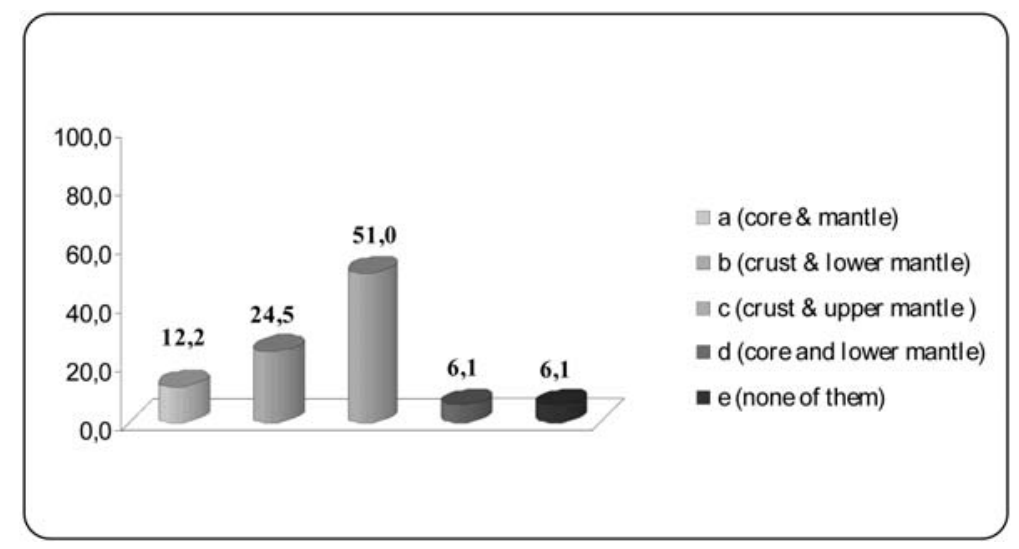

Fig. 4: Percentage of answers to 4th Question. 
In the $5^{\text {th }}$ and final question on the divergence of lithospheric plates (Table 5), the percentage of correct answers significantly reduced (32.7\%). It is worth to make two observations: a) The high percentage of all possible answers shows a complete confusion. Typically, the cumulative rate $28.6 \%$ answers geological unaccepted, such as that at the divergence boundary we expect to find deep earthquake zone or subduction zone. b) A significantly higher percentage of correct answers are observed in the question about the boundary of convergence (53.1\%) than the boundary of divergence (32.7\%) (Fig. 5).

Table 5.

\begin{tabular}{|c|c|}
\hline $\begin{array}{l}\text { 5th Question: When two tectonic plates diverge, we expect to find } \\
\text { at their boundary: }\end{array}$ & Answers \\
\hline a. deep earthquakes & 9 \\
\hline b. subduction zone & 5 \\
\hline c. mid-ocean ridge & 16 \\
\hline d. all of them & 9 \\
\hline e. none of them & 10 \\
\hline total & 49 \\
\hline
\end{tabular}

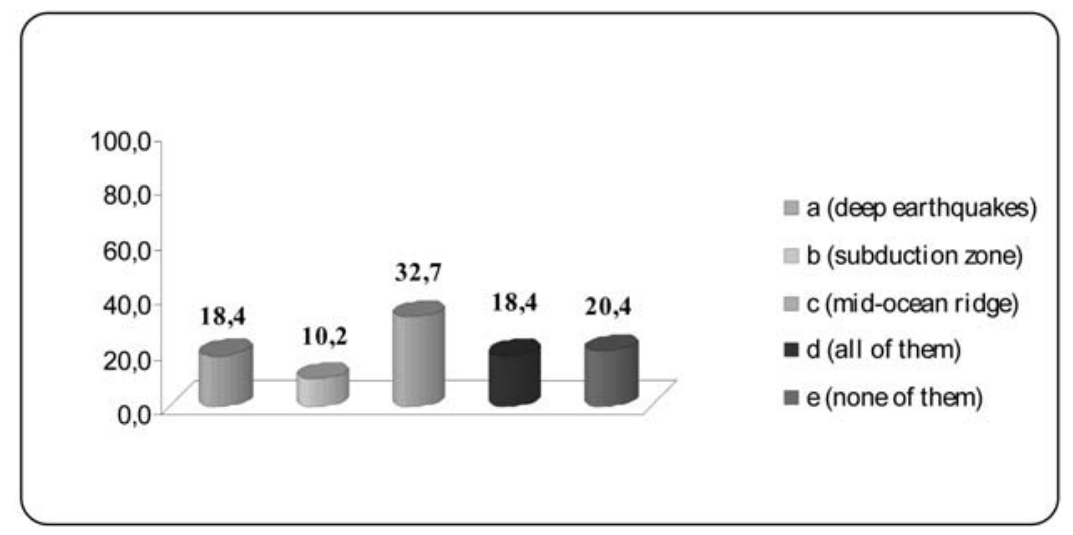

Fig. 5: Percentage of answers to 4th Question.

As the zero percentage of the reply that «the plates do not move» in two questions reveals, one of the key questions of research was answered positively by first-year students of Geology.

Whether this pre-existing perception is a part of the school-obtained knowledge or a result of the popularization of the theory of tectonic plates from the information media and society is a matter of further investigation.

One out of two students understands correctly the basic concepts of the theory of tectonic plates and the causes and effects of Geodynamic frame worldwide. This result agreed with similar studies about the conception owned by students (aged of 16-18) on tectonic plate's theory, according to international literature (King C., 2008).

About $50 \%$ of the questioned students understand with internal consistency and in a systematic way, both the geometry and the kinematics of the tectonic plates, with a satisfactory understanding of the rate at which these phenomena dynamically evolve. 


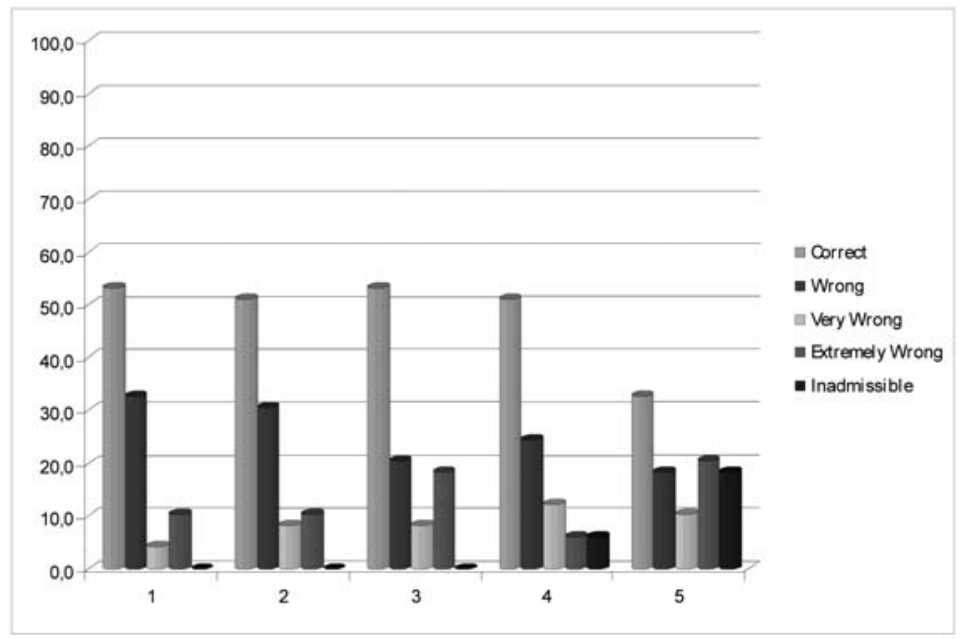

Fig. 6: Quantification of Conclusions.

One in four students has confused, without systematic knowledge and structure, getting information and data without a conceptual link, nor a deterministic result. This is a cognitive system which is a legacy from school knowledge as well as a wider social reality without any connection to the theory of tectonic plates.

One of the most interesting insights from this research is the fact that significant difference in the distribution of responses is observed between two similar questions about the convergent and divergent boundaries of tectonic plates.

We believe that the high percentage of correct answers to the question about the phenomena caused by the convergence of plates, compared with the corresponding low for the resulted phenomena of the divergence, demonstrates the effect of the fact that the Greek area is at a convergence boundary of the African and the Eurasian plate. Whether at school or from the information media and information, or otherwise in any form of simplified knowledge, it seems logical that we are better informed in geological phenomena on the convergence and less in the divergence of the plates, in our country (Greece).

In Greece, from textbooks to newspapers and magazines, there is a distinct orientation on the causes and effects of convergent margins rather than divergent. It is speculated that if the same survey was conducted in Iceland, the obtained results on convergence and divergence would be the opposite.

The conclusions could be summarized as:

All first-year students have satisfactory knowledge on the continuous movement of tectonic plates.

One out of two questioned students has systematic and consistent knowledge on the principles of the theory of tectonic plates, both at a conceptual and at a deterministic level, as well as in terms of geometric, kinematic and dynamic analysis.

One in four students has incomplete geological knowledge on the theory without any consistency and systematic approach.

The position of our country in the geodynamic frame determines the level of perceptions of students about the boundaries type of tectonic plates and this could explain the heterogeneity observed in the responses on the convergence and divergence (Fig. 6). 


\section{Acknowledgments}

The authors would like to thank Professor Spyros Pavlides, Department of Geology, AUTh., for his encouragement and facilitation on the above conducted research, which took place during the teaching hours of his lesson.

\section{References}

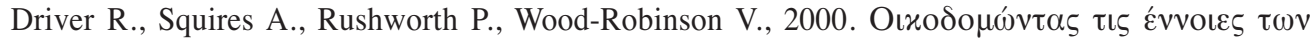

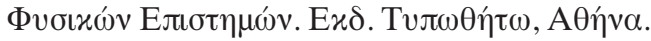

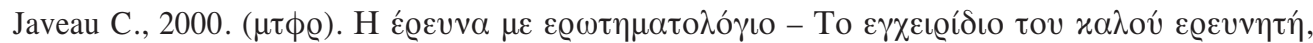
A $\theta \dot{v} v \alpha$.

King C., 2008, Geoscience education: an overview, Studies in Science Education, 44, 2, 187-222.

Piaget J., 1929. The child 's conception of the world. London: Routledge. 